\title{
GLOBAL DOS SISTEMAS FINANCEIROS: ANÁLISE DOS ACORDOS DE BASILEIA COMO UM INSTRUMENTO DE SOFT LAW PARA ASSEGUAR AESTABILIDADE FINANCEIRA INTERANCIONAL
}

\section{GLOBAL GOVERNANCE OF FINANCIAL SYSTEMS: ANALYSIS TOF HE BASEL ACCORDS AS A SOFT LAW TOOL TO ENSURE INTERNATIONAL FINANCIAL STABILITY}

\author{
${ }^{1}$ Alebe Linhares Mesquita \\ ${ }^{2}$ Jana Maria Brito Silva
}

\section{RESUMO}

O presente artigo se propõe a desenvolver um panorama geral dos Acordos de Capital de Basileia como um instrumento de soft law para assegurar estabilidade financeira internacional. Esta questão é analisada pela perspectiva da governança global que abrange as complexidades do sistema financeiro internacional moderno. Para tanto, este artigo é dividido em quatro seções principais. Em primeiro lugar, o fenômeno da governança global do sistema financeiro será explicado. Em segundo lugar, a arquitetura da regulação financeira internacional será delineada. Em terceiro lugar, o papel da soft law na regulação financeira internacional será investigado. Por fim, um panorama geral dos Acordos de Basileia de Adequação de Capital será dado. A metodologia adotada no desenvolvimento desta pesquisa caracteriza-se como teórica, bibliográfica, descritiva e exploratória. Em conclusão, pode-se afirmar que, devido a sua flexibilidade e agilidade, o soft law é um importante instrumento para responder às demandas da governança mundial e os Acordos de Basileia são uma boa iniciativa introdutória para regular mercados financeiros cada vez mais interconectados. Todavia, os Acordos por si só não podem garantir a estabilidade financeira mundial. Assim, faz-se necessário avançar em outros mecanismos de cooperação para melhorar a integridade do mercado e a confiança nos sistemas financeiros.

Palavras-chave: Governança global, Estabilidade financeira, Soft law, Acordos de basileia

\section{ABSTRACT}

This paper proposes to develop an overview of the Basel Capital Adequacy Accords as a soft law tool to ensure international financial stability. This issue is analyzed trough a global governance perspective that encompasses the complexities of the modern international financial system. Therefore, this article is divided into four main sections. Firstly, the

\footnotetext{
${ }^{1}$ Mestre em Direito Internacional pela Universidade de São Paulo - USP, São Paulo, (Brasil). Advogado no Instituto de Pesquisa Econômica Aplicada - DF, IPEA, Brasília, (Brasil). Email: alebe linhares@ hotmail.com

${ }^{2}$ Doutoranda em Direito Político e Econômico na Universidade Presbiteriana Mackenzie - MACKENZIE, São

Paulo, SP. (Brasil). Professora da Faculdade Católica Rainha do Sertão - FCRS, Ceará, CE. |E-mail.:

janamaria.brito@gmail.com
} 
phenomenon of the global governance of financial system will be explained. Secondly, the architecture of the international financial regulation will be delineated. Thirdly, the role of soft in financial regulation will be investigated. Lastly, an overview of the Basel Capital Adequacy Accords will be given. The methodology adopted in the development of this research is characterized as theoretical, bibliographical, descriptive and exploratory. In conclusion, it can be asserted that soft law, due to its flexibility and agility, is a meaningful

instrument to respond to the global governances demands and the Basel Accords are a good introductory initiative to regulate the increasing interconnected financial markets. However, they alone cannot assure the world financial stability. Hence, it is necessary to advance in other cooperation mechanisms to enhance market integrity and confidence in the financial systems.

Keywords/Palabras-claves/Mots-clés: Global governance, Financial stability, Soft law, Basel agreements

\section{INTRODUÇÃO}

Os bancos desempenham um papel primordial no funcionamento da economia mundial. Eles agem como um coração que mantém o sague fluindo por meio da centralização de quaisquer excedentes de capital e a sua realocação no círculo produtivo da economia. Um sistema financeiro estável proporciona um ambiente favorável para a alocação eficiente de recursos, promovendo crescimento econômico que pode ser revertido em desenvolvimento social.

Destarte, os países cada vez mais compreendendo a importância de um robusto e seguro sistema financeiro internacional para o crescimento da sua economia. No entanto, a atual cooperação internacional em matéria de regulação e supervisão financeira ainda se encontra em sua infância. Isso ficou patente durante a crise financeira de 2008, ocasionada, principalmente, por uma falha de fiscalização do mercado financeiro norte-americano, alastrando-se por outros países. Esse último colapso causou a pior recessão econômica dos últimos tempos e expôs lacunas, vulnerabilidades e erros na forma segundo a qual o setor financeiro é regulado internacionalmente.

Assim, quando deixados por sua própria conta, os mercados financeiros têm se apresentado como um fértil terreno para má conduta e pobres tomadas de decisões. A despeito de o risco ser uma característica inerente a este setor, as suas operações não podem se basear na lógica da capitalização dos lucros e nacionalização das perdas. Os contribuintes ao redor 
do mundo não devem ser prejudicados por decisões gananciosas e imprudentes das grandes corporações financeiras cuja única preocupação consiste em maximizar ainda mais os seus ganhos.

Nessa perspectiva, cumpre ressaltar que, nas últimas décadas, novas tecnologias permitiram que os bancos assumissem novas transações comerciais de qualquer parte do mundo a partir de um custo significativamente mais baixo. O sistema financeiro internacional tornou-se, assim, cada vez mais interconectado, aumentado os riscos sistêmicos e os efeitos pró-cíclicos. De fato, o capital informatizado flui com maior facilidade pelas fronteiras dos países do que bens ou serviços, sendo, assim, mais difícil de controlá-lo. Consequentemente, a falência de um banco local pode ter sérios impactos na economia mundial.

Diferentemente de outras áreas do Direito Internacional Econômico, como comércio, por exemplo, os acordos financeiros internacionais não tomam a forma de tratados juridicamente vinculantes. Pelo contrário, a maioria de suas normas e standards são convencionadas sob a forma de acordos informais não vinculantes, mais conhecidos como soft law. Normalmente, esses acordos são pactuados entre as respectivas agências regulatórias dos Estados sob os auspícios de instituições internacionais sem forma definitiva.

A partir da problemática acima descrita, este artigo objetiva, por meio de uma pesquisa teórica, bibliográfica, descritiva e exploratória, analisar como em que medida os Acordos de Basileia constituem instrumentos de soft law voltados a assegurar a estabilidade financeira internacional. Esta questão é analisada sob a perspectiva da governança global, de modo a englobar as reais complexidades do sistema financeiro moderno.

Por conseguinte, este artigo encontra-se dividido em quatro partes principais. Em um primeiro momento, discorre-se sobre a governança global no âmbito financeiro. Em seguida, delineia-se a arquitetura da regulação financeira internacional, apresentando os principais atores e instituições. Na sequência, investiga-se o papel do soft law como técnica para regulamentar operações bancárias transfronteiriças. Por fim, desenvolve-se uma análise introdutória dos Acordos de Basileia I, II e III. Destarte, pretende-se abordar esses e outros tópicos relacionados, em um esforço de se avançar na compreensão do direito financeiro internacional.

Cumpre ressaltar que este artigo não abordará diretamente as causas e consequências da crise de 2008, mas considera este evento como plano de fundo essencial às inferências desenvolvidas a partir de então. Ademais, este trabalho não pretende adentrar nas minúcias da regulamentação da adequação de capital. Isso exigiria conhecimentos de prática bancária, contabilidade e matemática, muito além do escopo deste artigo. Ao invés, propõe-se um 
ampla análise das principais características do Acordo de Basiléia, a fim de servir como um primeira leitura para advogados, estudantes e outros interessados.

A justificativa deste trabalho reside na relevância que as questões acima expostas apresentam na contemporaneidade. Afinal, encontrar um equilíbrio entre a redução da incidência de crises sistêmicas, sem excessivamente restringir a funcionalidade dos mercados financeiros apresenta-se como um dos maiores desafios do século XXI. Além do que, a construção de um resiliente sistema financeiro internacional impulsionaria o crescimento econômico global, que poderia ser revertido em desenvolvimento social entre as nações.

\section{A GOVERNANÇA GLOBAL DOS SISTEMAS FINANCEIROS}

Governança global consiste em um complexo processo que envolve múltiplos atores. Segundo Klabbers (2013, p. 17), governança global pode ser definida como o exercício de autoridade, em nível global, fora da regular estrutura legal. A expressão em si, explicam Weiss e Wilkinson (2014, p. 208), nasceu do casamento entre teoria acadêmica e prática política da década de noventa, vindo a se referir aos esforços coletivos para identificar, compreender e solucionar os problemas que ultrapassam as capacidades dos estados atuando individualmente.

Nesse sentido, cumpre observar que governança não é sinônimo de governo. Embora ambos os termos digam respeito a um comportamento finalístico com objetivos bem definidos de sistemas de regras, Rosenau (1992, p. 4) esclarece que governo implica atividades que são endossadas por uma autoridade formal, pelo poder de polícia, para garantir que as políticas sejam devidamente implementadas; já governança se refere a atividades apoiadas por objetivos comuns que podem, ou não, derivar de responsabilidades legais e formalmente estabelecidas e que não necessariamente dependem do poder de polícia para superar o desafio de alcançar a efetivação.

Assim, pode-se afirmar que governança constitui um fenômeno mais abrangente que governo, uma vez que não apenas abarca instituições governamentais mas também inclui mecanismos informais não-governamentais (ROSENAU, 1992, p. 4). Apesar de os Estados ainda manterem o direito soberano de não se obrigarem a nenhum acordo adotado pela maioria ou por todos os outros Estados, Zacher (1992, p. 60) afirma que, na prática, essa possibilidade está se tornando gradativamente mais difícil, haja vista que os países estão se 
tornando cada vez mais emaranhados em uma rede de interdependências e arranjos colaborativos dos quais a saída nem sempre é uma opção viável.

Nessa perspectiva, Weiss e Wilkinson (2014, p. 211) entendem governança global como a soma de ideias, formais e informais; valores; normas; procedimentos e instituições que ajudam todos os atores - Estados, Organizações Internacionais, sociedade civil e corporações multinacionais - a identificar, entender e solucionar problemas transfronteiriços. Na mesma linha, Finnamore (2014, p. 223) relembra que governar globalmente nunca será um ato solo, podendo acontecer por meio de diversos tipos de parcerias, como entre organizações internacionais e organizações não-governamentais (NGOs) locais, com diversificadas estruturas e resultados.

Ademais, Murphy (2014, p. 216) ressalta que, a partir de uma investigação histórica, pode se reconhecer que a governança global de hoje é bem diferente da de qualquer outra época anterior. Os rápidos avanços tecnológicos e o cada vez mais poderoso capitalismo industrial levou a uma expressiva expansão do seu escopo. Resolver muitos dos problemas globais da atualidade, como instabilidade financeira, aquecimento global e epidemias, exigirá que os países abram mão de parte de sua soberania para alcançar soluções que, de outra forma, não seriam capazes de serem atingidas independentemente (MORRIS, 2010, p. 611).

Nesse contexto, Zacher (1992, p. 84) ressalta que o período pós-Segunda Guerra Mundial tem sido marcado tanto pelo aumento dos lanços econômicos internacionais quanto pelos regimes regulatórios/colaborativos para gerenciá-los. Segundo o autor, uma das mais dramáticas expansões da interdependência econômica mundial ocorreu no sector financeiro que, impulsionado pelo aperfeiçoamento das tecnologias de informação, ganhou acesso a um mercado global que nunca dorme.

Atualmente, instituições financeiras são capazes de buscar ao redor do globo a transação comercial ideal que lhes garantirá os maiores retornos pelos menores custos (ZACHER, 1992, p. 84). Como notado por Davies e Green (2008, p. 8), novos instrumentos têm surgido, tornando possível a transferência de todos os tipos de risco, em uma escala muito maior e de uma forma muito mais complexa, não apenas por meio de derivativos mas também por meio de uma infinidade de outros mecanismos.

Nessa linha de raciocínio, Brummer (2012, p. 11-12) identifica 3 dinâmicas que ajudaram a elevar os fluxos de capital entre os países: (i) desregulamentação, associada à flexibilização das normas estatais sobre capital e produtos financeiros; (ii) tecnologia, que permite a transmissão de informações sobre valores mobiliários negociados em mercados estrangeiros via internet em tempo real; e (iii) inovação financeira, que faz com que seja 
possível a transferências de várias operações de risco em uma escala muito maior e para todas as partes do globo.

Consequentemente, nas últimas décadas, os mercados financeiros se tornaram cada vez mais integrados e internacionais em escopo. Essa alta interconectividade apresenta novos desafios para a governança global dos sistemas financeiros. Embora crises financeiras sejam um fenômeno recorrente, hoje em dia, elas parecem ser mais comuns e devastadoras do que em qualquer outra época da história (BRUMMER, 2012, p. 1).

As crises financeiras, explica Germain (2009, p. 671), não são definidas simplesmente pela volatilidade cambial e pelas estatísticas comerciais. Elas também são caracterizadas por uma queda significativa do valor da riqueza mundial e pela redução do volume das transações financeiras internacionais em um nível de atividade econômica mais amplo. Nessa acepção, Brummer (2012, p.1) relembra que "quando crises financeiras ocorrem, a economia mundial encolhe, empresas vão à falência e inúmeros empregos são perdidos, muitas vezes, em diferentes países e continentes."

Além do que, as crises financeiras normalmente tendem a tornar recessões piores do que um recuo natural do ciclo econômico. De acordo com Claessens e Kose (2014, p. 28), a duração média de uma recessão associada à uma crise financeira é cerca de 1.5 a 2 vezes maior do que uma recessão normal. Nesse aspecto em particular, recorda-se que a economia mundial ainda não se recuperou completamente da crise financeira de 2008 , de modo que seus efeitos ainda podem ser sentidas atualmente.

De acordo com Weber (2010, p. 684), a recente crise financeira demonstrou que as medidas e as iniciativas tomadas pelos Estados podem ser insuficientes para enfrentar grandes instabilidades sistêmicas. Assim, essas ações precisam ser acompanhas de esforços internacionais coordenados para combater a evolução da crise. As falhas de mercado, alegam Alexander, Dhumale, Eatwell (2006, p. 34), podem ocorrer devido ao risco sistêmico, o que é difícil para os Estados, agindo por conta própria, administrá-los de forma eficaz em razão dos seus altos custos de transação.

Devido à natureza interconectada e pluralista dos regimes regulatórios, Riles (2014, p. 1) afirma que um dos desafios centrais à regulação do sistema financeiro internacional reside em como administrar o impacto das instituições financeiras globais sistemicamente importantes ${ }^{1}$ na economia mundial. Essas instituições, explica Guttmann (2014, p.7), operam como um cartel, extraindo grandes rendas de monopólios a partir da combinação de diferentes 
tipos de finanças sob um mesmo arcabouço operacional. A sua falência pode abalar significativamente diversos sistemas bancários ao redor do globo, representando uma ameaça real à estabilidade financeira mundial (GU; LIU, 2014, p. 142). Essas instituições financeiras caracterizam-se como grandes demais para falir (too-big-to-fail) e, consequentemente, desfrutam de acesso privilegiado às autoridades monetárias de diversos países.

Reconhecendo todas essas vulnerabilidades, Weber (2010, p. 695) afirma que "estabilidade financeira tornou-se uma preocupação comum no processo de globalização, uma vez que ela está diretamente ligada com prosperidade econômica e com o bem-estar humano." Logo, com o propósito de se avançar o entendimento sobre como a governança global dos sistemas financeiros é exercida, faz-se necessário compreender a arquitetura da regulação financeira internacional, suas principais instituições e competências.

\section{A ARQUITETURA DA REGULAÇÃO FINANCEIRA INTERNAICONAL}

A governança financeira mundial contemporânea é composta por uma diversa gama de atores internacionais (WOUTERS; ODERMATT, 2014, p. 52). Como observado por Brummer (2012, p. 68), o sistema de regulação internacional é formado por: entidades que se especializam na definição de agendas para o sistema regulatório internacional, organismos que concentram função de standard-setting em si, e instituições que monitoram o sistema e verificam o cumprimento das disposições regulatórias.

Cumpre ressaltar que, depois da crise de 2008, a estrutura da regulação financeira internacional sofreu significativos ajustes. Assim, a fim de se obter uma noção inicial de como o sistema funciona, ilustra-se a atual arquitetura da regulação financeira internacional

\footnotetext{
${ }^{1}$ Global Systemically Important Financial Institutions - G-SIFIs

${ }^{2}$ De acordo com Howard Davies, a arquitetura financeira mundial é formada por uma rede das seguintes
} 
na figura abaixo.

Arquitetura Financeira Mundial Pós-crise $2008^{2}$

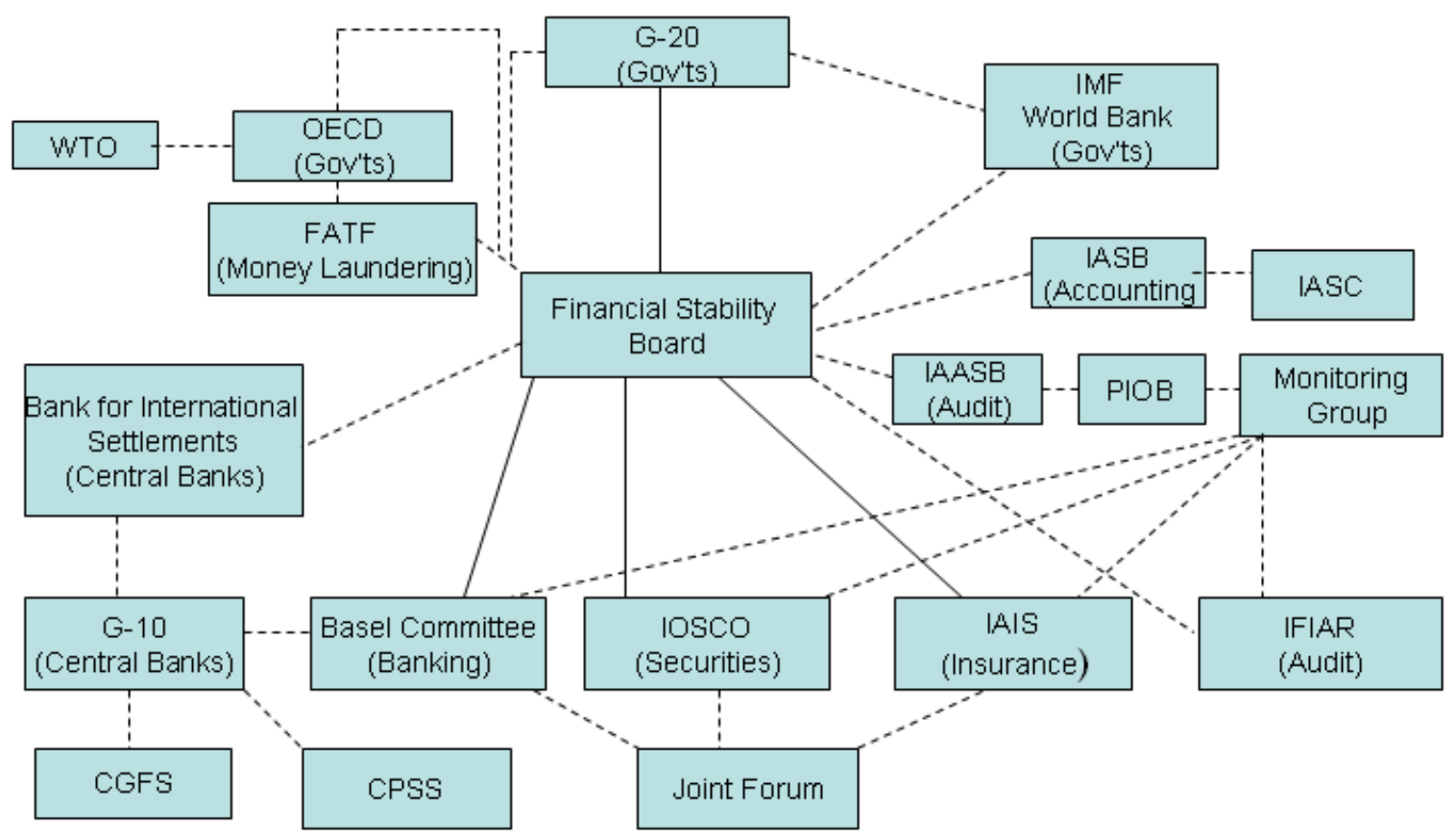

Fonte: DAVIES, 2010.

Como pode se observar, a arquitetura financeira mundial compreende uma teia de diversas entidades internacionais, sem uma clara hierarquia entre elas. Essa estrutura inclui atores políticos (G-20), organizações internacionais (FMI, OMC, BIRD) e organismos internacionais que atuam por meio de soft law (FSB). Assim, para se entender essa rede, devese investigar a divisão funcional de trabalho que informa as atividades regulatórias e as responsabilidades de cada ator (BRUMMER, 2012, p. 69).

Esta seção propõe apontar as competências dos principais atores envolvidos na governança global dos mercados financeiros. Dado o curto espaço e a grande quantidade de entidades internacionais, não será possível analisá-las todas. Todavia, um quadro geral dos principais atores será delineado, de modo que uma ampla compreensão possa ser alcançada.

\footnotetext{
${ }^{2}$ De acordo com Howard Davies, a arquitetura financeira mundial é formada por uma rede das seguintes entidades internacionais, como: Governos do G20, Bancos Centrais do G10, Fundo Monetário Internacional (FMI), Banco Mundial (BIRD), Organização Mundial do Comércio (OMC), Bank for International Settlements (BIS), Organization for Economic Co-operation and Development (OECD) Governments, Financial Stability Board (FSB), Basel Committee on Baking Supervision, International Association of Insurance Supervisors (IAIS), International Forum of Independent Regulators (IFIAR), Financial Action Task Force (FATF), International Accounting Standards Board (IASB), Public Interest Oversight Board (PIOB), International Organization of Securities Commissions (IOSCO), Committee on the Global Financial System (CGFS), Committee on Payment and Settlement Systems (CPSS).
} 
Uma primeira observação a esse respeito é destinada ao Grupo dos 20 (G20). O clube, explica Brummer (BRUMMER, 2012, p. 70), tem a sua origem em uma série de encontros convocados pelos ministros da finanças da França, do Japão, do Reino Unido, do Estados Unidos e da Alemanha Ocidental (G5) no início da década de 1970, em resposta aos desafios econômicos. Desde então, o grupo se expandiu, ${ }^{3}$ permanecendo como uma reunião voluntária entre os países envolvidos (THOMPSON, 2014).

O G20 é um órgão que, por si só, não se baseia em nenhum tipo de tratado internacional formal ou qualquer outro instrumento. Seus líderes se reúnem anualmente, enquanto os seus ministros das finanças e governadores dos bancos centrais se reúnem regularmente para "discutir formas de fortalecer a economia global, reformar as instituições financeiras internacionais, melhorar a regulação financeira e implementar as reformas econômicas fundamentais" (THE GROUP OF 20, 2015).

Na sua última cúpula em Brisbane (Austrália), os chefes de Estado dos países do G20 manifestaram intenção de progredir em quatro áreas centrais da regulação financeira, quais sejam: (i) reduzir os riscos e impactos de quando instituições sistemicamente importantes são ameaçadas de falência; (ii) lidar com os riscos dos bancos paralelos, melhorando a transparência e, quando apropriado, aumentando sua regulação; (iii) tornar os mercados de derivativos mais seguros, aumentando sua transparência por meio da melhoria dos seus relatórios; e (iv) construir instituições financeiras resilientes a partir da implementação dos dispositivos de Basileia III (THE GROUP OF 20, 2014).

À luz destes propósitos, os países reafirmaram a sua disposição para resolver coletivamente as principais questões que colocam a estabilidade financeira do mundo em risco. Devido a sua importância para um sistema bancário internacional mais seguro, esses objetivos tornaram-se prioridades máximas desde a crise de 2008.

No plano das Organizações Internacionais formalmente constituídas, destacam-se as três organizações primeiramente pensadas durante a Conferência de Bretton Woods de 1994, quais sejam: o Fundo Monetário Internacional (FMI), o Banco Mundial (BIRD) e a Organização Mundial do Comércio $(\mathrm{OMC})^{4}$. Segundo Amaral Júnior (2013, p. 422), a

\footnotetext{
${ }^{3}$ Atualmente, o G20 financeiro é formado pela União Europeia mais 19 países: África do Sul, Alemanha, Arábia Saudita, Argentina, Austrália, Brasil, Canadá, China, França, Índia, Indonésia, Itália, Japão, República da Coréia, México, Rússia, Turquia, Reino Unido e Estados Unidos.

conferência delineou a ordem econômica internacional que prevaleceu depois da Segunda Guerra Mundial, a partir da remoção dos obstáculos que permeavam as relações econômicas
} 
internacionais do período entre guerras.

O Fundo Monetário Internacional foi instituído primeiramente com o objetivo de garantir o equilíbrio do sistema monetário internacional. Atualmente, afirmam Wouters e Odermatt (2014, p. 52), o FMI contribui para a estabilidade macro econômica por meio de apoio e aconselhamento aos países que enfrentam dificuldades de pagamentos externos, bem como, por meio da adoção de medidas, durante tempos de crises, que ajudem a prevenir contágio internacional, mantendo um sistema econômico mais estável.

No mais, Alexander, Dhumale e Eatwell (2006, p. 80) ressaltam que os artigos do Acordo Constitutivo do FMI $^{5}$ concedem poderes para a Organização Internacional supervisionar o sistema monetário internacional, a fim de garantir que suas operações ocorram de forma eficaz. Destarte, o Fundo exerce vigilância sobre as políticas cambiais de seus Estados-Membros. Essa atividade de supervisão, afirma Brummer (2012, p. 91), "foi idealizada para proporcionar um canal de diálogo, persuasão e pressão para estimular políticas domésticas que sirvam tanto para o interesse do Estado-Membro quanto para contribuir para a estabilidade e prosperidade internacional."

O Banco Internacional para Reconstrução e Desenvolvimento (BIRD), mais tarde conhecido como Banco Mundial, também exerce um importante papel na governança global dos mercados financeiros. O seu Acordo Constitutivo busca promover o desenvolvimento econômico dos países por meio da concessão de empréstimos que estão condicionados à implementação de programas de ajustes macro econômicos conjuntamente com reformas institucionais (ALEXANDER; DHUMALE; EATWELL, 2006, p. 80).

\footnotetext{
${ }^{4}$ Apesar de a concepção de uma organização internacional voltada à regulação do comércio ter sido pensada no âmbito da Conferência de Bretton Woods, a Organização Mundial do Comércio (OMC) só foi criada em 1994 por meio da adoção do Acordo de Marraqueche. A Carta de Havana, que previa o estabelecimento da Organização Internacional do Comércio (OIC) nunca entrou em vigor, devido, principalmente à resistência do congresso norte-americano de ratifica-la.

${ }^{5}$ Artigo $1^{\circ}$ do Acordo Constitutivo do FMI estabelece os propósitos para os quais o fundo foi criado. Eles incluem: a promoção da cooperação internacional, a expansão e o crescimento equilibrado da cooperação monetária internacional, a expansão e o crescimento equilibrado do comércio internacional, a estabilidade cambial e o estabelecimento de um sistema multilateral de pagamentos (INTERNATIONAL MONETARY FUND, 2015).
} 
Desde então, destacam Wouters e Odermatt (2014, p. 58), o papel do Banco Mundial evoluiu de um tradicional financiador (lender) para um moderno formular de políticas globais. Atualmente, o Banco apresenta grupos de trabalho com expertise em um vasta gama de assuntos, dentre os quais destaca-se o da regulamentação do sistema financeiro.

Nesse domínio, o Banco Mundial é responsável por identificar se, e em que medida, os reguladores nacionais cumprem com a legislação financeira internacional. Como destacado por Brummer (2012, p. 92), o Banco Mundial, conjuntamente com o FMI, administram o Programa de Avaliação Financeira (Financial Assessment Program - FSAP) que, por meio da avaliação e monitoramento dos mercados financeiros dos Estados-Membros, desenvolve estratégias e políticas públicas para fortalecer os seus sistemas.

A Organização Mundial do Comércio, por sua vez, também desempenha um importante papel na liberalização do setor financeiro internacional. Apesar de não ter sido estabelecida com o objetivo de assegurar a estabilidade financeira internacional, mas para avançar no processo de liberalização comercial, Wouters e Odermatt (2014, p. 53) destacam que a OMC contribui para um sistema internacional mais estável como um todo.

Além do que, o Acordo Geral sobre o Comércio de Serviços (General Agreement on Trade in Services - GATS) "promove a liberalização do comércio transfronteiriço de sistemas financeiros ao exigir que os Estados-Membros reduzam as barreiras ao comércio de serviços financeiros de acordo com um calendário específico de compromissos negociados" (ALEXANDER; DHUMALE; EATWELL, 2006, p. 80). Assim, a OMC ajuda a alocar bancos no exterior, aumentando a densidade e interconexão do sistema financeiro.

Por fim, o Financial Stability Board - FSB foi criado, na esteira da crise financeira de 2008, por meio de uma decisão dos líderes do G20, durante sua cúpula de Londres em abril de 2009. ${ }^{6}$ Os líderes do G20 decidiram que era preciso "estabelecer maior consistência e cooperação sistemática entre os países e o regime de padrões internacionais acordados que um sistema financeiro global requer" (DÉLÉGATION DE L'ÚNION EUROPÉENNE AUPRÈS DES NATIONS UNIES, 2009). O documento constitutivo do FSB caracteriza-se como um memorando de entendimento que, ao contrário de um tratado, não impõe obrigações legais

\footnotetext{
${ }^{6} \mathrm{O}$ artigo $1^{\mathrm{o}}$ da Carta do FSB estabelece os objetivos do conselho, que envolvem a coordenação das autoridades financeiras nacionais e organismos internacionais de normatização para promover e aplicar políticas ao setor financeiro. O FSB também é encarregado de colaborar com instituições financeiras internacionais para resolver as vulnerabilidades do sistema financeiro internacional (FINANCIAL STABILITY BOARD, 2015).
} 
internacionais aos seus membros ${ }^{7}$ que são formados por representantes dos bancos centrais dos membros do G20 (WOUTERS; ODERMATT, 2014, p. 55).

O FSB, afirmam Wouters e Odermatt (2014, p. 55), sucede o Financial Stability Forum - FSF, instituído pelos ministros de finança e representantes dos bancos centrais do G7 em 1999, na sequência da crise financeira asiática, caracterizando-se, assim, como a primeira inovação do renovado G20. Mais significativamente, assevera Brummer (2012, p. 73), o foco regulatório do FSB passou de regulação micro-prudencial para macro-prudencial, de modo que "a organização não é mais exclusivamente voltada a determinas empresas ou setores, mas encarregada de examinar os níveis de alavancagem do sistema financeira como um todo."

Por conseguinte, explica Riles (2013, p. 18-24), a metodologia de trabalho do FSB desenvolve-se em três elementos-chave: (i) projetos de elaboração de normas, (ii) revisãopelos-pares (peer-review) e (iii) coordenação firme e específica. No que tange à elaboração de normas, o FSB patrocina normas gerais, regras de ouro (rules of thumb) e melhores práticas ao invés de regras rígidas e específicas. O método de revisão-pelos-pares, por sua vez, constitui uma técnica de soft law para implementar padrões regulatórios harmonizados a partir do relatório dos países sobre os seus progressos em executar as normas que, em seguida, são avaliados por um comitê de pares. Por fim, os colégios de supervisores visam a regulação transfronteiriça das instituições financeiras e, em particular, a coordenação de reguladores nacionais e internacionais.

Segundo Davies (2014), o FSB age como uma aranha no centro da teia financeira internacional, analisando o sistema como um todo e tentando identificar vulnerabilidades que possam causar problemas futuros. Os seus relatórios periódicos ao G20 reuni as diversas vertentes de regulação de uma forma clara e compreensível. Todavia, o FSB não tem poderes de executar suas medidas, ou seja, ele não pode obrigar reguladores nacionais forcem os Estados-Membros a cumprir as suas orientações.

Em consonância com Wouters e Odermatt (2014, p. 55), o Financial Stability Board, caracterizar-se-ia como o quarto pilar da governança econômica global, juntamente com o FMI, o Banco Mundial e a OMC. No entanto, Lastra (2014) argumenta que, apesar disso ser sinalizado por muitos autores, o FSB permanece um organismo normalizador internacional sem reais poderes ao invés de uma organização internacional formal. A estrutura informal do 
FSB apresenta-se em nítido contraste com os outros pilares, os quais são instituídos com base em tratados internacionais e gozam de personalidade jurídica internacional (WOUTERS; ODERMATT, 2014, p. 55).

Em suma, pode-se afirmar que a arquitetura da regulação financeira global retrata uma teia de múltiplas entidades legais internacionais. Embora algumas delas não sejam propriamente organizações interestatais constituídas por tratados ou mesmo acordos executivos, Slaughter (2004, p. 38) afirma que elas constituem redes trans-governamentais que se tornaram suficientemente formais para justificar o título de associação ou organização, disponde de uma equipe de funcionários e reuniões regulares.

Além do mais, não se deve subestimar o profundo engajamento dos ministros de finanças e representantes dos bancos centrais nessas redes trans-governamentais, cujo objetivo reside em responder, substancialmente se não formalmente, às demandas para um nova arquitetura financeira. De fato, em alguns casos, são os próprios ministros, não os chefes do executivo, que conduzem a agenda da governança global do sistema financeiro internacional.

Nessa perspectiva, Slaughter (2004, p. 38) defende que a conexão entre esses reguladores, como representantes de bancos centrais, comissários de valores mobiliários e os supervisores de seguros, em suas respectivas organizações - O Comitê de Basiléia, $\operatorname{IOSCO}^{8}$ e IAIS $^{9}$ - representa uma das melhores evidências do Estado desagregado (Disaggregated State).

Como demonstrado, uma parte significativa da governança global do sistema financeiro é posta em prática por meio de mecanismos de soft law. Assim, faz-se necessário avançar na explicação do que viria a ser esse instrumento, como ele funciona e qual o seu papel na regulação financeira internacional.

\footnotetext{
${ }_{7}^{7}$ Argentina, Austrália, Brasil, Canadá, China, França, Alemanha, Autoridade Monetária de Hong Kong, Índia, Indonésia, Itália, Japão, México, Holanda, República da Coreia, Rússia, Arábia Saudita, Singapura, África do Sul, Espanha, Suíça, Turquia, Reino Unido, Estados Unidos da América e União Europeia.
} 


\section{O PAPEL DO SOFT LAW NA REGULAÇÃO FINANCEIRA INTERNACIONAL}

O Direito Internacional contemporâneo compreende uma complexa combinação de direito consuetudinário, positivo, declarativo e soft law (CHINKIN, 2003). Na prática, os Estados formalizam acordos ou instituições de diferentes formas a fim de atingir os objetivos desejados. O soft law, como definido por Raustalia e Slaughter (2002, p. 551), "são instrumentos ou regras que têm alguns indícios de direito internacional, mas lhe faltam força vinculante explícita e acordada."

A expressão soft law, no entanto, permanece controversa entre os acadêmicos. ${ }^{10}$ Independentemente da designação terminológica que deva ser dada a esse fenômeno ${ }^{11}$, Raustiala e Slaughter (2002, p. 551) chamam atenção para a aparente proliferação de instrumentos de soft law, bem como para o crescente interesse dos estudiosos em explorar as vantagens e desvantagens do hard e do soft law na tomada de decisão dos Estados.

Nesse sentido, Reincke e Witte (2003, p. 77) afirmam que os acordos internacionais não vinculantes não são necessariamente uma alternativa aos acordos internacionais vinculantes ou à cooperação interestatal, pelo contrário, eles normalmente representam um primeiro importante elemento do processo evolutivo que molda as relações jurídicas entre múltiplos atores, facilitando e aumentado a eficácia e a eficiência de políticas transnacionais.

Consequentemente, apesar de o soft law apresentar menor credibilidade que outras normas vinculantes, ele fornece a flexibilidade necessária em condições de incerteza (RAUSTIALA; SLAUGHTER, 2002, p. 551). Os instrumentos de soft law são capazes de fornecer uma solução experimental para novos desafios à medida que eles surgem. Assim, eles podem preencher as lacunas de outros instrumentos legalmente vinculantes sem a necessidade de se entrar em um laborioso processo de alteração de tratado, por exemplo (REINCKE; WITTE, 2003, p. 110). Nesse sentido, Raustiala e Slaugther (2002, p. 552) salientam que os acordos de soft law não são tratados falidos, mas podem ser uma escolha institucional superior.

\footnotetext{
${ }_{9}^{8}$ International Organization of Securities Commissions.

${ }^{9}$ International Association of Insurance Supervisors.
} 
Outro atraente aspecto dos instrumentos de soft law para a globalização residem no fato de eles poderem regular o comportamento de atores não-estatais, desde gigantes multinacionais a ONGs e indivíduos (REINCKE; WITTE, 2003, p. 110). No sistema tradicional, sublinham Reincke e Witte (2003, p. 110), as ONGs e as empresas transnacionais não produzem Direito. No entanto, na busca por soluções para os desafios da globalização, esses atores acham no soft law as rápidas e flexíveis respostas de que eles precisam. É por isso que, de acordo com os autores, "os novos formuladores de políticas globais se voltam para o soft law como uma eficaz ferramenta de transição para concordar e articular normas e princípios não vinculantes” (REINCKE; WITTE, 2003, p. 109).

Ademais, é importante notar que o soft law se apresenta em uma variedade infinita de formas. Em sua grande maioria, ele é expresso da forma escrita, mas, de acordo com Chinkin (2003, p. 25), princípios não escritos, como cortesia e boa-fé, também podem ser incluídos. Em que pese as incontáveis formas pelas quais o soft law se manifeste, Brummer (2010, p. 628-630) afirma que ele pode ser classificado de acordo com três gêneros básicos: (i) melhores práticas, que promovem supervisão regulatória por meio de regras de ouro (rules of thumb); (ii) relatórios regulamentares e observações, que ajudam a estabelecer um base para políticas públicas e, normalmente, geram correntes normativas que ajudam a definir a adequação de abordagens regulatórias nacionais; e (iii) compartilhamento de informação e cooperação, em que as autoridades nacionais se comprometem a melhorar a coordenação com os seus pares para aprimorar a sua supervisão e monitoramento prudencial.

Nessa perspectiva, afirmam Raustiala e Slaugther (2014, p. 552), o soft law cria uma regime fundamental para o diálogo, no qual os Estados, por sua vez, podem alterar a concepção dos seus interesses e até mesmo sua identidade. Em última instância, um acordo sobre normas juridicamente vinculantes se torna possível. De fato, ressalta-se a crescente relevância do soft law na governança global dos sistemas financeiros.

\footnotetext{
${ }^{10}$ Hass e Bilder questionam a coerência e utilidade da expressão soft law, particularmente, quando aplicada para designar instrumentos e normas juridicamente não vinculantes. Segundo os autores, parece-lhes inadequada a utilização do termo soft law para descrever normas e instrumentos normativos que não estão claramente em forma jurídica e que não se destinam a ser obrigatórias. Logo, o termo não se encaixaria em nenhum dos sentidos usualmente entendidos para a palavra Direito. Tendo isto em mente, os estudiosos defendem a preferência pela utilização das expressões soft international norms ou non-binding norms ao invés de soft law. Vide: HAAS; BILDER, 2003, p. 72.

${ }^{11}$ Daqui em diante, a expressão soft law é empregada como acordos normativos que não são juridicamente vinculantes.
} 
Nesse aspecto em específico, Alexander, Dhumale e Eatwell (2006, p. 143) relembram que a maioria das normas e padrões internacionais para regulação e supervisão bancária evoluíram de instrumentos voluntários não vinculantes para um status cada vez mais preciso e obrigatório, apoiado tanto por incentivos oficiais e mercadológicos quanto por sanções. $\mathrm{Na}$ mesma linha, Brummer (2010, p. 624) afirma que o direito financeiro internacional parte de noções tradicionais de direito internacional público de informalidade, podendo, de fato, demonstrar-se mais "duro" do que a sua qualidade de soft-law possa sugerir.

Nesse sentido, ressalta-se que a regulação financeira, segundo Davies e Green (2008, p. 10), significa, principalmente, “os processos de autorização, regulamentação e supervisão de instituições financeiras e o mercado de negócios no qual elas operam." Normalmente, afirma Weber (2010, p. 685), “o foco da regulação financeira reside na prevenção de crises e na manutenção da estabilidade financeira, ou seja, na segurança e na solidez do sistema financeiro."

Assim, o propósito do direito bancário é garantir que os bancos sejam prudentemente dirigidos, com capital e liquidez adequados, e que estejam envolvidos em atividades comerciais seguras e delimitadas que não comprometam indevidamente a saúde do banco (BRUMMER, 2012, p. 8). Para alcançar esses objetivos, os múltiplos atores que participam da governança global dos sistemas financeiros costumam usar o soft law como seu principal instrumento regulatório.

De acordo com Brummer (2010, p. 634), especialmente no contexto da regulação financeira, o "soft law permite que as partes experimentem e, se necessário, mudem a direção quando novas informações e custos surjam." Além do mais, o soft law serve como um mecanismo de comunicação por meio do qual os países podem sinalizar uns aos outros a sua intenção em adotar uma medida ou uma abordagem regulatória específica (BRUMMER, 2010, p. 634).

Os standards, relembra Riles (2013, p. 76), são tidos como instrumentos preferíveis à regulação financeira global, haja vista que "eles permitem pluralismo (para diferenças em estratégia nacional e ênfase) dentro de um regime de determinadas bases de referência comuns e valores regulatórios compartilhados." Além disso, os padrões também são vistos como mais flexíveis do que as regras e, assim, mais capacitados para solucionar problemas futuros que não podem ser previstos no momento da elaboração da regra (RILES, 2013, p. 76). 
Nessa perspectiva, Gu e Liu (2014, p. 151-152) afirmam que duas lógicas conduzem a escolha de soft law pelos estados: soberania e incerteza jurídica. A primeira permite que os países preservem as suas prerrogativas nacionais, podendo ser exercidas sobre o assunto em questão. A segunda se baseia no fato de que reformas financeiras internacionais evoluem rapidamente, gerando novos e complexos problemas em fluxo. Logo, legisladores nacionais tendem a aceitar a forma do soft law quando se trata de regulação financeira internacional, a fim de se permitir flexibilidade necessária para situações instáveis.

De acordo com Alexander, Dhumale, Eatwell (2006, p. 137), o soft law internacional permanecerá viável como um instrumento para reformar a regulação financeira internacional porque a ausência de um obrigação legal fornece aos reguladores e aos organismos de normatização a flexibilidade necessária para responder rapidamente aos avanços dos mercados financeiros e implementar padrões não vinculantes de uma maneira que atenda às necessidades das suas jurisdições.

Assim, pode-se argumentar que, provavelmente, o futuro cumprimento do soft law internacional continue a ser conduzido pelas forças institucionais e construtivistas, desde que a globalização e democratização continuem (HAAS; BILDER, 2003, p. 64). Em suma, Reincke e Witte (2003, p. 113) afirmam que "o soft law atende a muitas das necessidades de governança global, pois é um meio de incluir todos os atores relevantes, tentar encontrar soluções que ainda se apresentam como experimentais e regular com maior flexibilidade e rapidez."

Por exemplo, quando se trata do uso de soft law na regulação financeira, o primeiro exemplo que vem em mente é a adoção dos Acordos de Basileia de Adequação de Capital. Por conseguinte, a fim de entender como instrumentos de soft law regulam os sistemas financeiros internacionais, faz-se necessário delinear uma visão geral dos Acordos e dos seus principais dispositivos.

\section{DE BASILEIA I A BASILEIA III: UMA VISÃO GERAL}

Tendo em vista que a literatura sobre os Acordos de Basileia é vasta e complexa, este capítulo se propõe a desenvolver uma primeira análise introdutório, discorrendo sobre seu escopo, natureza, principais características e limitações das suas normas, bem como informar e contextualizar o papel do soft law na regulação financeira internacional. Não se pretende assim esgotar o assunto, mas proporcionar uma primeira compreensão sobre a matéria. 
Para tanto, deve se ter em mente que a principal questão tratada em todos os Acordos de Basileia reside em definir o que vem a ser capital e quanto dele deve ser mantido pelos bancos. ${ }^{12}$ As negociações começaram, em meados da década de 80 , entre os três países mais preocupados com a questão das filiais estrangeiras: Estados Unidos, Reino Unido e Japão. O objetivo inicial, afirmam Davies e Green (2008, p. 37), restringia-se a chegar a uma base comum para medir e definir capital, o que poderia, então, ser utilizado como base para o reconhecimento mútuo, a fim de se permitir que um banco internacional se estabelecesse em um mercado estrangeiro sem ter que rever seu capital separadamente.

Assim, depois de longas negociações sobre os auspícios do Bank for International Settlement - BIS ${ }^{13}$, o documento intitulado International Convergence of Capital Measurement and Capital Standards, agora geralmente referido como Acordo de Capital de Basileia, ou simplesmente Basileia I, entrou em vigor em 1988. O Acordo foi originalmente assinado pelos países do G-10 14 , mas recebeu consideráveis adesões posteriormente (HO,2002, p. 648).

Os dois principais objetivos da iniciativa foram: reforçar a solidez e a estabilidade do sistema bancário internacional e diminuir as fontes de desigualdade concorrencial existente entre os bancos internacionais (BALTHAZAR, 2006). Nesse sentido, Lowenfeld (2011, p.

825) afirma que "Basileia I parte do princípio de que existe uma relação direta entre a solidez dos bancos e a sua base de capital." Por essa razão, o acordo é estruturado em quatro componentes-chave: (i) uma definição de capital; (ii) um regime de deduções; (iii) uma abordagem de ponderação de risco e (iv) um índice de solvabilidade de capital a partir da ponderação do risco dos ativos (DOCHERTY; VIORT, 2014, p. 118).

\footnotetext{
${ }^{12}$ Segundo Lowenfeld $(2011$, p. 820), capital, quando aplicado a bancos ou mesmo a qualquer negócio, significa a quantidade residual disponível aos acionistas comuns após todos os outros créditos, de credores e outros, foram satisfeitos. Em outras palavras, Brummer (2012, p. 213) explica que capital representa uma parte dos ativos do banco que não tem qualquer compromisso contratual associado para reembolso.

${ }^{13}$ O Basel Committee on Banking Supervision foi concebido como um fórum de cooperação em matéria de supervisão bancária entre os seus países membros. O seu objetivo consiste em aumentar a estabilidade financeira por meio da melhoria do know-how de supervisão e da qualidade da supervisão bancária mundial. Os países são representados no Comitê pelos seus respectivos bancos centrais (BANK FOR INTERNATIONAL SETTLEMENTS, 2014).
} 
Em consonância com Jones (2014, p.7), a principal característica do Acordo de Basileia I é a instituição de um conjunto de requisitos mínimos de capital de $8 \%$, com base nos ativos ponderados pelo risco. A intenção era garantir que os bancos detivessem, individualmente, ativos suficientes para enfrentar riscos operacionais sem requerer intervenção governamental. As regras, destaca Balthazar (2006, p. 17), “foram desenhadas para definir um nível mínimo de capital, mas os supervisores nacionais poderiam implementar requisitos mais rígidos."

Surpreendentemente, argumentam Docherty e Viort (2014, p. 121), esse número não foi sujeito a intensos estudos analíticos, como seria de se esperar de um distinto organismo internacional como o Comitê da Basileia. Na verdade, o percentual de $8 \%$ foi determinado de acordo com os níveis médios de capital do sistema naquele tempo, bem como com o desejo dos bancos de se tornarem mais resilientes a estresses financeiros. Todavia, estudos posteriores demonstraram que o nível estabelecido estava aproximadamente correto, considerando os objetivos da política e a tolerância, naquela época, para falência bancária.

Após estabelecer o coeficiente de solvabilidade do capital, definiu-se o que poderia ser considerado como capital. Para este efeito, explica Balthazar (2006, p. 17), reconheceu-se duas classes de capital a partir da função de sua qualidade: Capital Nível 1 (Tier 1 Capital), ou capital principal; e Capital Nível 2 (Tier 2 Capital), ou capital suplementar. A tabela abaixo discrimina a que se refere a cada tipo de capital.

\begin{tabular}{|l|l|}
\hline \multicolumn{2}{|c|}{ Tabela 1: Definição de Capital } \\
\hline \multirow{2}{*}{ Nível 1 } & Capital Integralizado \\
\cline { 2 - 2 } & Reservas Evidenciadas (lucros retidos, reservas legais) \\
\hline & Reservas não divulgadas \\
\hline
\end{tabular}

\footnotetext{
${ }^{14}$ Bélgica, Canadá, França, Alemanha, Itália, Japão, Holanda, Suécia, Suíça, Reino Unido, Estados Unidos e
} Luxemburgo.

\begin{tabular}{|l|l|}
\hline \multirow{2}{*}{ Nível 2 } & Reservas de reavaliação de ativos \\
\cline { 2 - 2 } & Provisões Gerais \\
\cline { 2 - 2 } & Instrumentos Híbridos (devem ser sem garantia, totalmente integralizados) \\
\cline { 2 - 2 } & $\begin{array}{l}\text { Dívida Subordinada (máximo 50\% de Nível 1, mínimo 5 anos - fator de desconto para } \\
\text { vencimentos mais curtos) }\end{array}$ \\
\hline \multirow{2}{*}{ Deduções } & Ágio (do Nível 1) \\
\cline { 2 - 2 } & Investimentos em subsidiárias não consolidadas (de Nível 1 e Nível 2) \\
\hline
\end{tabular}

Fonte: BALTHAZAR, 2006, p. 18.

Nessa perspectiva, Docherty e Viort (2014, p. 118) relembram que pelo menos metade do montante do capital regulatório total deveria se constituir de Capital Nível 1 e não mais do que a metade poderia compreender Capital Nível 2. Em outras palavras, cada banco deve deter um capital de pelo menos $8 \%$, dos quais pelo menos metade, ou seja, $4 \%$ dos ativos 
deve ser de capital primário ou Nível 1 (LOWENFELD, 2011, p. 825-826). Essa fórmula é esclarecida na tabela abaixo:

\section{Tabela 2. Fórmulas de Capital do Acordo de Basileia I}

Total do Nível 1 de capital $\geq 4 \%$ dos ativos ponderados pelo risco

Fonte: BRUMMER, 2012, p. 214.

Ademais, tendo em vista que certos tipos de ativos são claramente menos arriscados do que outros, o capital deve ser ponderado de modo a refletir a incerteza de cada operação. Essa abordagem de ponderação do risco, explicam Docherty e Viort (2014, p. 120), divide os ativos em grupos que, então, têm um fator de ponderação sobre eles aplicados. Esse cálculo resulta em um valor total de ativos ponderados pelo risco, sobre o qual as exigências de capital são definidas. Destarte, as exposições de risco são atribuídos a um dos cinco grupos de risco de ponderação $(0,10,20,50$ e $100 \%)$, como demonstrado na tabela 3 .

Nível $1+$ Nível 2 capital $\geq 8 \%$ dos ativos ponderados pelo risco

\begin{tabular}{|c|l|}
\hline \multicolumn{2}{|c|}{ Tabela 3: Ponderação dos Riscos dos Ativos } \\
\hline \multirow{2}{*}{0} & Item \\
\cline { 2 - 2 } 0 & Dinheiro \\
\cline { 2 - 2 } & Créditos de governos centrais da OCDE \\
\cline { 2 - 2 } & $\begin{array}{l}\text { Créditos de outros governos centrais se forem expressas e financiadas em moeda nacional (para evitar o } \\
\text { risco de transferência entre países) }\end{array}$ \\
\hline \multirow{2}{*}{20} & Créditos de bancos da OCDE e de bancos multilaterais de desenvolvimento \\
\cline { 2 - 3 } & Créditos de bancos fora da OCDE com prazo de vencimento residual < 1 ano \\
\cline { 2 - 2 } & Créditos do setor público de países membros da OCDE \\
\hline 50 & Empréstimos hipotecários \\
\hline 100 & $\begin{array}{l}\text { Todos os outros créditos de empresas; créditos de bancos de países não-membros da OCDE com prazo de } \\
\text { vencimento > 1 ano; ativos fixos; e todos os outros ativos. }\end{array}$ \\
\hline
\end{tabular}

Fonte: BALTHAZAR, 2006, p. 18

Por fim, o último componente do Basel I, o regime de deduções, ajustou as diferenças entre a abordagem contábil e a prudencial, removendo, por exemplo, a conta de ágio da conta de capital total do banco (DOCHERTY; VIORT, 2014, p. 118). Assim, os reguladores não poderiam simplesmente usar o patrimônio contábil de um banco como medida de capital. "Em vez disso, definiu-se uma série de ajustes que poderiam ser aplicados ao balanço contábil para dar maior sentido às medidas de regulação de capital" (DOCHERTY; VIORT, 2014, p 119). 
O Acordo de Basileia I estabeleceu o final do ano de 1992 como prazo para que os bancos implementassem o índice de capital acordado (LOWENFELD, 2011, p. 826). Em setembro de 1993, o Comitê emitiu um comunicado confirmando que os bancos do G10 com significativos negócios internacionais já estavam cumprindo com as exigências mínimas estabelecidas no Acordo (BANK FOR INTERNATIONAL SETTLEMENT, 2014). Ademais, a despeito de o Acordo ser supostamente voltado aos bancos internacionalmente ativos, muitos países aplicaram-no também em nível bancário nacional (BALTHAZAR, 2006, p. 17).

Como observado por Jones (2014, p. 4), “apesar de Basileia I nunca ter sido projetado para se aplicar aos bancos em outras jurisdições, ou até mesmo em bancos nacionais dos países do G10; no início da década de 90 mais de 120 países já tinham aderido ao Acordo ou declarado a sua intenção de fazê-lo". Assim, “esse regime foi introduzido não apenas nos países membros mas também em praticamente todos os outros países com bancos internacionalmente ativos" (BANK FOR INTERNATIONAL SETTLEMENT, 2014). Cumpre destacar que o acordo alcançado em 1988 não era vinculante, uma vez que, como outros acordos dessa natureza, nenhum país estava em posição para comprometer o seu parlamento nacional a consentir com o que tinha sido acordado (DAVIES; HOWARD, 2008, p. 38).

No final dos anos 90, havia um reconhecido e generalizado entendimento de que Basileia I não estava produzindo os efeitos esperados, uma vez que as regras de atribuição de risco eram, em grande parte, muito grosseiras (JONES, 2014, p. 4). Sobre esse aspecto, Brummer (2012, p. 215) afirma que "o sistema de ponderação de risco era um tanto quanto arbitrário e não conseguia distinguir completamente o risco entre credores pertencentes a mesma categoria de risco.” Ademais, Docherty e Viort (2006, p. 122) argumentam que Basel I tornou-se obsoleto à medida que o setor sobre o qual se aplicava tornou cada vez mais sofisticado.

Assim, no final dos anos 90, entidades reguladoras nacionais e o Comitê da Basileia propuseram a revisão do Basileia I, de modo que, em 2004, um conjunto definitivo de propostas foi finalmente acordado. Conforme informado por Balthazar (2006, p. 40), os objetivos de Basel II consistiam em: aumentar a qualidade e a estabilidade do sistema financeiro internacional; criar e manter a igualdade de condições entre os bancos internacionalmente ativos; e promover a adoção de práticas mais rigorosas em matéria de gestão de riscos. 
Para estes fins, o Acordo de Basileia II baseia-se em três pilares complementares de adequação de capital. Como explicado por Davies e Green (2008, p. 43), estes são:

Pilar I: Exigências mínimas de capital, com base na aplicação de coeficientes de risco sobre os ativos do banco. A exigência do Pilar I inclui capital para suportar riscos de crédito, de mercado e operacionais.

Pilar II: Revisão Supervisória (Supervisory review), que inclui uma avaliação do sistemas de controle e de gestão de riscos do banco, que podem resultar em um ajuste da exigência de capital do Pilar I, tanto para mais quanto para menos.

Pilar III: Disciplina de Mercado, incluindo regras mais rigorosas e detalhadas sobre divulgação e transparência.

Todos os três pilares, afirmam Docherty e Viort (2014, p. 124), foram pensados como mutuamente dependentes, em outras palavras, qualquer um dos três pilares não funciona sem os outros dois. Na verdade, afirma Lowenfeld (2011, p. 835), Basileia II mantém a fundamental exigência de capital mínimo do Acordo Basileia I, mas promove algumas importantes alterações em como os bancos determinam a contribuição de coeficientes para a quantificação de riscos para além do puro risco de crédito e na melhoria da divulgação desses dados para o público.

De acordo com Jones (2014, p. 42), uma grande diferença entre Basileia I e II reside na possibilidade de os Bancos, sob a abordagem Advanced-Internal Ratigns Based (A-IRB), utilizarem os seus próprios modelos para estimar vários aspectos do risco de crédito. No entanto, como somente os maiores bancos tinham a capacidade institucional de fazê-lo, os bancos menores tiveram que adotar uma abordagem padronizada, especificada no Acordo de Basileia II. Essencialmente, essa metodologia consiste em uma versão mais refinada da prevista por Basileia I, ligando categorias de risco mais detalhadas a classificações externas de crédito fornecidas por agências de classificação de risco (JONES, 2014, p. 42).

Em síntese, Balthazar (2006, p. 48) cita as 6 mais importantes inovações trazidas por Basileia II, quais sejam: (i) o aumento da sensibilidade dos requisitos de capital para níveis de risco; (ii) a introdução de necessidades de capital regulamentar para risco operacional; (iii) a maior flexibilidade do Acordo, a partir da delegação de decisões aos reguladores nacionais; (iv) o aumento do poder dos reguladores nacionais, facultando-os, sob o Pillar II, avaliar a adequação do capital do banco a partir do seu perfil de risco específico; (v) a melhoria do reconhecimento de técnicas de redução de risco; e (vi) a obrigação de se divulgar, detalhadamente, exposições de risco e políticas de mitigação de risco. 
Logo, pode-se afirmar que Basileia II avançou consideravelmente na regulação financeira internacional em comparação a Basileia I. Entretanto, essas medidas não foram suficientes para prevenir o mundo da recente crise financeira global. Mesmo antes de o Banco Lehman Brothers entrar em colapso em setembro de 2008, a necessidade de um substancial fortalecimento do regime do Basileia II já era discutido (BANK FOR INTERNATIONAL SETTLEMENT, 2004).

Como observado por Jones (2014, p. 9), as falhas de Basileia II tornaram-se rapidamente perceptíveis. A utilização da abordagem A-IRB pelas maiores instituições financeiras, por exemplo, proporcionou-lhes maior vantagem competitiva em detrimento das pequenas instituições, que utilizavam a abordagem padronizada. Além disso, estudos apontavam que a permissão do uso da metodologia A-IRB pelos maiores bancos levaria a uma dramática queda dos seus níveis de capital. Esses problemas se somavam a existência de provas credíveis de que o intenso lobby das grandes instituições financeiras tinha resultado em um Acordo Basileia II mais favorável aos grandes bancos internacionais.

Em uma análise pós-crise, o Comitê de Basileia chegou a um consenso de que as principais causas para sua deflagração foram: a excessiva alavancagem, as fracas bases de capital, os pobres perfis de financiamento e os insuficientes amortecedores de liquidez (DOCHERTY; VIORT, 2014, p. 141). Tentando resolver esses e outros problemas mais amplos relacionados à supervisão pré-crise, novas reformas foram acordadas em 2010 no âmbito de Basileia III. Em síntese, este último Acordo estabelece mecanismos que asseguram aos bancos melhores recursos financeiros para operar; bem como aumenta a capacidade do setor financeiro de absorver choques decorrentes de estresse econômico, seja qual for a fonte, reduzindo, assim o risco de alastramento de um crise financeira para a economia real (BANK FOR INTERNATIONAL SETTLEMENT, 2014).

Diferentemente do que ocorreu na transição de Basileia I para Basileia II, Docherty e Viort (2014, p. 142) ressaltam que Basileia III deixa a estrutura de Basileia II em grande parte intacta, promovendo as maiores mudanças na definição de capital. Nesse aspecto em particular, Jones (2014, p. 10) explica que, sob Basileia III, o requisito de capital mínimo permanece em $8 \%$, mas há um aumento no requisito mínimo de capital social (common equity) de $2 \%$ para $4,5 \%$ do total de ativos ponderados. Ademais, as definições de capital social e de capital Nível 1 foram restringidas.

Aliás, a fim de se reduzir o efeito pro-cíclico, Basileia III exige que os bancos mantenham um "amortecedor" (buffer) de conservação de capital de 2,5\% em adição aos 
requisitos mínimos de capital acima descritos. Essa medida eleva os requisitos de capital social total para 7\% do capital mínimo. Além disso, Basel III introduz um "amortecedor" voluntário de capital anticíclico de 0 a 2,5\%, projetado para se acumular durante os períodos de rápido crescimento de crédito agregado. O objetivo desses mecanismos é assegurar que os bancos mantenham capital suficiente que possa ser utilizado para absorver as perdas durantes períodos estresse sem atingir os requisitos mínimos de capital (JONES, 2014, p. 11). Esse novo regime estabelecido pelo Basileia III encontra-se ilustrado no seguinte gráfico.

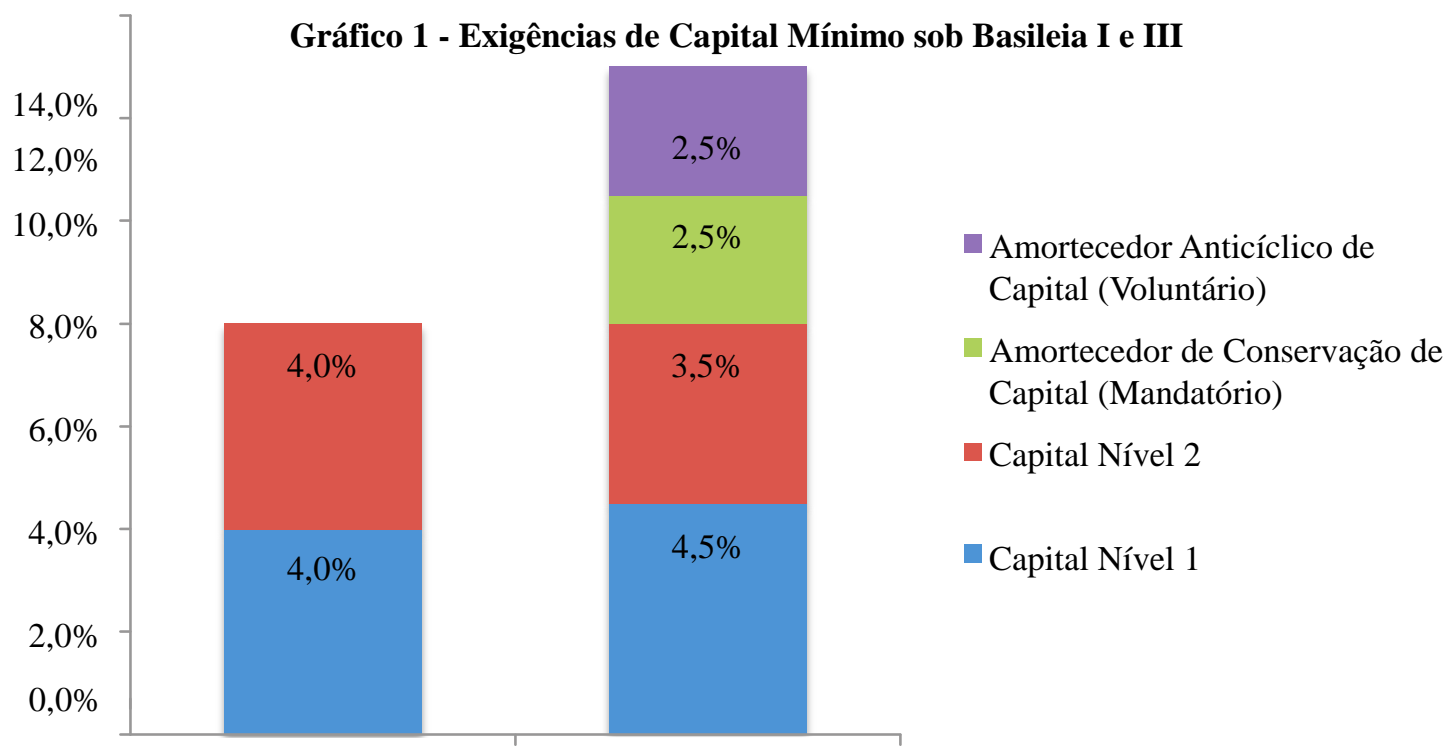

Exigência de Capital Mínimo - Basileia I Exigência de Capital Mínimo - Basileia III

Fonte: Acordos de Basileia I e III. Elaboração pelos autores.

Logo, se todos os requisitos forem cumpridos, o capital mínio pode chegar a $13 \%$ do ativo do banco. As medidas serão introduzidas lentamente, somente entrando em vigor em 2019. Com o propósito de possibilitar o cumprimento dos novos standards ao mesmo tempo em que se apoia a recuperação da economia mundial, disposições transitórias de 2013 a 2018 também foram previstas (BANK FOR INTERNATIONAL SETTLEMENT, 2015).Por fim, cumpre ressaltar que tanto Basileia I quanto Basileia II ainda estão em vigor, de modo que o regime jurídico instituído pelos Acordos de Basiléia devem ser interpretados e aplicados conjuntamente. 


\section{CONCLUSÃO}

A governança global dos mercados financeiros refere-se aos esforços coletivos para identificar, compreender e resolver os problemas transfronteiriços que ameaçam a estabilidade do sistema bancário internacional. A sua arquitetura é sustentada por um conjunto diversificado de atores que formam uma rede dispersa e sem uma clara hierarquia entre os atores. A fim de reforçar a sua cooperação, faz-se necessário que o sistema de regulação e supervisão em construção reflita os valores fundamentais da segurança financeira, da confiança nos sistemas e da integridade do mercado.

Só então poder-se-á reduzir os impactos negativos das crises financeiras internacionais e diminuir a frequência com a qual elas ocorrem. Ao maximizar as vantagens que um sistema bancário globalizado pode proporcionar, o mundo poderia se beneficiar de um excedente significativo de capital para investir em áreas estratégicas voltadas ao desenvolvimento social e sustentável dos países. Como um sistema circulatório, o setor bancário fornece o batimento necessária para que a economia mundial continue respirando.

Assim, maior atenção deve ser dada aos mecanismos internacionais de controle e vigilância. Como demonstrado, o soft law domina grande parte da regulação financeira da atualidade. Em uma indústria tão dinâmica e inovadora quanto a financeira, o soft law atende às necessidades de flexibilidade, agilidade e informalidade que a governança global requer. Ademais, ele fornece o espaço suficiente para que todas as partes interessadas participem na construção de soluções experimentais para problemas emergentes.

Nessa perspectiva, os Acordos de Basileia são um bom exemplo de como o soft law permeia a regulação financeira internacional. A despeito de esses Acordos não terem sido capazes de impedir a última crise e, provavelmente, também não serão aptos a prever a próxima, eles representam um importante avanço na cooperação entre os Estados na tratativa de questões altamente sensíveis que ameaçam a estabilidade financeira internacional. Portanto, eles devem ser apoiados e expandidos. A sua periódica atualização é extremamente importante para acompanhar as frequentes inovações dos serviços bancários.

Nesse aspecto em particular, cumpre ressaltar que, devido à constate e rápida evolução dos serviços financeiros, a regulação do desempenho de bancos internacionais não é uma tarefa fácil. A inovação apresenta-se como uma estratégia-chave para ganhar novos nichos de mercado. Assim, instituir um único rígido regime que abarque todo o espectro da atividade financeira demonstra-se extremamente difícil. É por isso que, atualmente, o soft law 
se apresenta como uma ferramenta bem sucedida na governança global dos mercados financeiros.

Como se pode inferir, todas as indicações demonstram que as interdependências financeiras internacionais só tendem a aumentar, de modo que regimes cada vez mais robustos serão necessários para gerencia-las. Logo, administra-las com sucesso requererá ações que não são unilaterais, bilaterais ou mesmo plurilaterais, mas sim globais. Nesse aspecto, demonstra-se interessante fortalecer a eficiência e coordenação entre os atores internacionais, a fim de garantir um sistema financeiro estável. Atualmente, essa premissa representa o principal objetivo da governança global dos sistemas financeiros.

Em conclusão, pode-se afirmar que o soft law, devido a sua flexibilidade e agilidade, caracteriza-se como um importante instrumento para responder às demandas da governança global. Os Acordos de Basileia, por sua vez, apresentam-se como uma boa iniciativa preliminar para regular os mercados financeiras cada vez mais interconectados. Entretanto, os Acordos, por si só, não podem garantir a estabilidade financeira internacional. Por isso, faz-se necessário avançar em outros mecanismos de cooperação que melhorarem a integridade do mercado e a confiança nos sistemas financeiros.

\section{REFERÊNCIAS}

ALEXANDER, Kern; DHUMALE, Rahul, EATWELL, John. Global Governance of Financial Systems: the international regulation of systemic risk. Oxford: Oxford University Press, 2006.

AMARAL JÚNIOR, Alberto. Curso de Direito Internacional Público. 4 ed. São Paulo: Atlas, 2013.

BALTHAZAR, Laurent. From Basel 1 to Basel 3: the integration of state-of-art risk modeling in banking regulation. New York: Palgrave Macmillan, 2006.

BANK FOR INTERNATIONAL SETTLEMENTS. A Brief History of the Basel Committee. Outubro 2014. BIS. Disponível em: < http://www.bis.org/bcbs/history.pdf>. Acesso em: 9 jun. 2015.

- Basel II: International Convergence of Capital Measurement and Capital Standards: a Revised Framework. Junho 2004. BIS. Disponível em: < http://www.bis.org/publ/bcbs107.htm>. Acesso em: 9 jun. 2015.

Basel Committee On Banking Supervision: Basel III phase-in arrangements. BIS. Disponível em: < http://www.bis.org/bcbs/basel3.htm>. Acesso em: 9 jun. 2015.

BRUMMER, Chris. Soft Law and the Global Financial System: rule making in the $21^{\text {st }}$ 
century. Cambridge: Cambridge University Press, 2012.

. Why Soft Law Dominates International Finance - and not Trade. Journal of

International Economic Law, v. 13, n. 3, p. 623-646, set. 2010.

CHINKIN, Christine. Normative Development in the International Legal System. In: SHELTON, Dinah (Ed.). Commitment and Compliance: the role of non-binding norms in the international legal system. Oxford: Oxford University Press, 2003.

CLAESSENS, Stijn; KOSE, Ayhan. Financial Crises: explanations, types, and implications. IMF Working Paper, WP/13/28, jan. 2013. Available at: <http://www.imf.org/external/pubs/ft/wp/2013/wp1328.pdf>. Acesso em: 30 dez. 2014.

DAVIES, Howard. The Spider of Finance. Project Syndicate. Nova York, 16 out. 2014a. Disponível em: <https://www.project-syndicate.org/commentary/financial-stability-boardimpact-by-howard-davies-2014-10> Acesso em: 3 jan. 2015.

Regulating the Financial Markets: Lessons, Challenges, and Prospects in the Aftermath of the World Crisis. Apresentação Powerpoint exibida no Cairo em 12 de Dezembro de 2010. Disponível em: <www.lse.ac.uk/aboutLSE/.../ppt/Cairo12Dec2010.ppt>. Acesso em: 15 nov. 2014.

DAVIES, Howard; GREEN, David. Global Financial Regulation: the essential guide. Cambridge: Polity Press, 2008.

DÉLÉGATION DE LÚNION EUROPÉENNE AUPRÈS DES NATIONS UNIES. G20 London Summit: official communique. EU@UN. Disponível em: < http://euun.europa.eu/articles/fr/article_8622_fr.htm>. Acesso em: 6 jan. 2015.

DOCHERTY, Adrian; VIORT, Franck. Better Banking: understanding and addressing the failures in risk management, governance and regulation. Chichester: Wiley, 2014.

FINANCIAL STABILITY BOARD. Charter of the Financial Stability Board. FSB. Disponível em: <http://www.financialstabilityboard.org/wpcontent/uploads/r_120809.pdf?page_moved=1>. Acesso em: 17 nov. 2014.

FINNEMORE, Martha. Dynamics of Global Governance: building on what we know. International Studies Quartely, v. 58, n. 1, p. 221-224, mar. 2014.

GERMAIN, Randall. Financial Order and World Politics: crisis, change and continuity. International Affairs, v. 85, n. 4, p. 669-867, jul. 2009.

GU, Bin; LIU, Tong. Enforcing International Regulatory Reforms. Journal of International Economic Law, v. 17, n. 1, p. 139-176, fev. 2014.

GUTTMANN, Robert. Emerging Makerts and the Nexus of Global Finance. Centre d'Economie de l'Université Paris Nord. Paris, jan. 2014. Disponível em: < http://www.cepn-paris13.fr/epog/wp-content/uploads/2014/10/GUTTMANN2_Meta-Viewof-Imbalances-Guttmann.pdf>. Acesso em: 27 dez. 2014.

HAAS, Peter; BILDER, Richard. Compliance Theories Choosing to Comply: theorizing from international relations and comparative politics. In: SHELTON, Dinah (Ed.). Commitment 
and Compliance: the role of non-binding norms in the international legal system. Oxford: Oxford University Press, 2003.

HO, Daniel. Compliance and International Soft Law: why do countries implement the Basel Accord? Journal of International Economic Law, v. 5, n. 3, p. 647-688, ago. 2002.

INTERNATIONAL MONETARY FUND. Articles of Agreement of the International Monetary Fund. IMF. Disponível em: < https://www.imf.org/external/pubs/ft/aa/\#art1>. Acesso em: 9 jun. 2015.

JONES, Emily. Global Banking Standards and Low Income Countries: helping or hindering effective regulation? Global Economic Governance, University of Oxford, GEG Working Paper 2014/91, set. 2014. Disponível em: <http://www.globaleconomicgovernance.org/sites/geg/files/GEG\%20WP_91\%20Banking\%2 0Standards\%20and\%20Low\%20Income\%20Countries_Emily\%20Jones.pdf >. Acesso em: 9 jun. 2015.

KLABBERS, Jan. International Law. Cambridge: Cambridge University Press, 2013. LASTRA, Rosa. Do we need a World Financial Organization? Journal of International Economic Law, v. 17, n. 4, p. 787-805, nov. 2014.

LOWENFELD, Andreas. International Economic Law. Cambridge: Cambridge University Press, 2011.

MORRIS, Ian. Why the West Rules - For Now: the patterns of history and what they reveal about the future. New York: Farrar, Straus and Giroux, 2010.

MURPHY, Craig. Global Governance over the Long Haul. International Studies Quarterly, v. 58, n. 1, p. 216-218, mar. 2014.

RAUSTIALA, Kal; SLAUGHTER, Anne-Marie. International Law, International Relations and Compliance. Princeton Law \& Public Affairs, paper n. 02-02, p. 538-558, nov. 2002. Disponível em: < http://papers.ssrn.com/sol3/papers.cfm?abstract_id=347260>. Acesso em: 9 jun. 2015.

REINCKE, Wolfgang; WITTE, Jan. Challenges to the International Legal System Interdependence, Globalization, and Sovereignty: the role of non-binding international legal accords. In: SHELTON, Dinah (Ed.). Commitment and Compliance: the role of nonbinding norms in the international legal system. Oxford: Oxford University Press, 2003.

RILES, Annelise. Is New Governance the Ideal Architecture for Global Financial Regulation? Institute for Monetary and Economic Studies. Tokyo, jan. 2013. Discussion Paper n. 2013E-1. Disponível em: 〈http://www.imes.boj.or.jp/research/papers/english/13-E-01.pdf>. Acesso em: 9 jun. 2015.

ROSENAU, James. Governance, Order, and Change in World Politics. In: ROSENAU, James; CZEMPIEL, Ernst-Otto (Ed.). Governance without Government: order and change in the world politics. Cambridge: Cambridge University Press, 1992.

SLAUGHTER, Anne-Marie. A New World Order. Princeton: Princeton University Press, 
2004.

THE GROUP OF 20. About G20. G20. Disponível em: < https://g20.org/about-g20/>. Acesso em: 8 jun. 2015.

Disponível

Policy Note: Building Financial Resilience. 16 Novembro 2014. G20.

<http://dev2.dpmc.gov.au/official_resources/policy_note_building_financial_resilience>.

em:

Acesso em: 8 jun. 2015.

THOMPSON, Robert. Financial Regulation's Architecture within International Economic Law. Journal of International Economic Law, v. 17, n. 4, p. 807-822, dez. 2014.

WEBER, Rolf H. Multilayered Governance in International Financial Regulation and Supervision. Journal of International Economic Law, v. 13, n. 3, p. 683-704, out. 2010.

WEISS, Thomas; WILKINSON, Rorden. Rethinking Global Governance? Complexity, Authority, Power, Change. International Studies Quarterly, v. 58, n. 1, p. 207-2015, mar. 2014.

WOUTERS, Jan; ODERMATT, Jed. Comparing the "Four Pillars" of Global Economic Governance: a critical analysis of the institutional design of the FSB, IMF, World Bank, and WTO. Journal of International Economic Law, Oxford, v. 17, n.1, p. 49-76, mar. 2014.

ZACHER, Mark. The Decaying Pillars of the Westphalian Temple: implications for international order and governance. In: ROSENAU, James; CZEMPIEL, Ernst-Otto (Ed.). Governance without Government: order and change in the world politics. Cambridge: Cambridge University Press, 1992. 